\title{
External Powered Orthoses for Paraplegic Subjects: A Meta Analysis Review
}

\author{
Mohammad Taghi Karimi ${ }^{1}$ and Amir Esrafilian ${ }^{2}$ \\ ${ }^{1}$ Orthotics and Prosthetics, Rehabilitation Faculty of Isfahan University of Medical Sciences, Isfahan, Iran \\ ${ }^{2}$ Mechanical Engineering, Isfahan University of Technology, Isfahan, Iran
}

Correspondence should be addressed to Amir Esrafilian, esrafilian@gmail.com

Received 10 January 2012; Accepted 22 March 2012

Academic Editors: K. Nas, A. Rainoldi, and H. Unalan

Copyright (C) 2012 M. T. Karimi and A. Esrafilian. This is an open access article distributed under the Creative Commons Attribution License, which permits unrestricted use, distribution, and reproduction in any medium, provided the original work is properly cited.

\begin{abstract}
Background. Various types of external powered orthoses have been designed to improve the function of paraplegic subjects; however it is not clear which one of them has better performance. Therefore, the aim of this paper is to evaluate the function of available external powered orthoses based on the research presented in the relevant literature. Method. An electronic search was done via the Pubmed, Embase, and ISI Web of Knowledge data from 1960 to 2010. The quality of the research studies was evaluated by use of Black and Down tool. The performances of the orthoses are evaluated based on the gait analysis, stability analysis, and energy consumption analysis. Results. Although various types of external powered orthoses have been designed to improve the performance of spinal cord injury individuals, there are a few research studies in this regard. Moreover, they have a poor quality. Conclusion. There is no research study regarding the performance of spinal cord injury subjects with the external powered orthoses. It is recommended to do clinical trial studies to evaluate the performance of these orthoses.
\end{abstract}

\section{Introduction}

Spinal cord injury (SCI) is damage or trauma to spinal cord that results in loss of function, mobility, and sensation below the level at which the spinal cord has been injured. This disorder is characterized according to amount of functional loss, sensation loss, and inability of a SCI individual to stand and walk [1-3]. The incidence of this disorder varies between 12.7 and 59 new cases per million each year [4-6]. The total population of individuals with SCI in the UK and USA is 40,000 and between 183,000 and 230,000, respectively [7]. These patients can use various types of orthoses and wheelchair to transfer from place to place. It has been shown that walking with an orthosis brings some benefits for the patients which include decreasing bone osteoporosis, prevention of pressure sores, and improving the function of digestive system $[8,9]$.

A variety of orthoses have been designed in order to improve the ability of the subjects to stand and walk, such as the mechanical orthoses, external powered orthoses, functional electrical stimulation, and hybrid system which is a combination of an orthosis and electrical stimulation
[8, 10-20]. To the authors' knowledge, the performance of SCI individuals while standing and walking with the mechanical orthoses is low. Moreover, the patients experience some problems in terms of energy consumption and high loads which are applied on upper limb during walking [21-23].

The external powered systems employ various kinds of power source which include pneumatic, hydraulic, and electrical powers. However, the main question posted here is how much the performance of the SCI subjects differs from that with the external powered system, while walking with the mechanical orthoses. Moreover, it is not clear how much is the willingness of the subjects to use the orthoses. Therefore, the main aim of this paper is to determine the performance of SCI individuals in use of external powered orthoses based on the studies presented in the literature.

\section{Method}

An electronic search was done via Pubmed, Embase, and ISI Web of Knowledge data base from 1960 to 2010. The abstracts and title of each individual study were assessed by 
two reviewers. A first selection of the relevant studies was done based on whether the title or abstract addressed the research questions of interest. The second selection was done according to the following criteria:

(a) experimental studies published in English,

(b) addressing the walking of paraplegic subjects with external powered orthosis.

2.1. Assessment of Quality of the Research Studies. The quality of various research studies undertook in this regard was assessed by use of the Down and Black tool. Two expert reviewers were asked to evaluate the quality of each research study. The correlation between the review results was assessed by use of Pearson correlation test. The correlation between the reviewer results was 0.9 ( $P$ value 0.03$)$. The sensitivity of this test was studied by some investigators. Moreover, the difference between the results of research studies (heterogeneity) was evaluated. This has been done to determine whether the difference between the results of various studies is as a result of sampling error or due to presence of heterogeneity.

As the number of studies in this paper was small, a significant point of 0.1 rather than the conventional level of 0.05 was used to determine statistical significant. A low $P$ value or a large chi-square (relative to degree of freedom) provides heterogeneity of intervention effects (variation in effect estimates beyond chance). A rough guide which was used in this paper was low, moderate, and high at values $0,0.25,0.5$, and 0.75 , respectively (see Figure 1 ).

\section{Results}

A total number of 50 relevant papers have been found based on the keywords as external powered orthosis, spinal cord injury, and rehabilitation. After considering the selected criteria, only 25 papers were selected for final analysis. Most of the papers focus on introducing the orthosis without undertaking any clinical test. Only 5 papers covered the data of gait parameters while walking with external powered orthoses. It was impossible to check the heterogeneity of the most research studies, as only two of them focus on evaluating of the same orthosis. The results of various research studies were categorized based on gait analysis, stability analysis, and also energy consumption. As the number of research studies was too limited, a brief description of the orthosis was done.

3.1. Pneumatic Active Gait Orthosis (PAGO). This orthosis developed at the Department of Mechanics of Polytechnic di Trino and consists of two main parts which include a passive support structure and a pneumatic actuation system control and produce motion in the hip and knee joints. An ankle foot orthosis (AFO) immobilizes the ankle joint in natural position. The source of power for forward progression in this orthosis is compressed air. There was also a control system that regulates the function of the system according to the gait pattern [18].

3.2. Powered Gait Orthosis (PGO). This orthosis was designed by Ryu et al. (2004) and consists of two pneumatic muscles actuators, a compressed air system, and joint angle sensors [24].

3.3. Weight-Bearing Control Orthosis (WBCO). This orthosis was based on this concept to provide more dynamic reciprocal gait pattern for patients especially for those with a high lesion level. The orthosis consists of four main parts which include a control system, a variable foot floor walking, a reciprocal link device, and a metal structure $[25,26]$.

3.4. Two Degrees of Freedom Motor Powered Gait Orthosis (TDFMPO). This orthosis was based on advanced reciprocal gait orthosis and consists of some actuators to produce motion in the knee joint. The motion of the hip was enhanced by use of a motor powered mechanism [27].

3.5. Driven Gait Orthosis (DGO). It was designed by Hocoma, at Rehabilitation Centre of University Hospital Balgrist in Zurich. This consists of an orthosis which was connected to a rigid frame of a treadmill. There are two drivers on each leg which move the hip and knee joints. The performance of the drivers was controlled by a real-time system which is running on a personal computer [19].

3.6. Hybrid Assistive Limb (HAL). In the most recent model, HAL-5 structure consists of a frame made of nickel molybdenum and aluminum alloy. Some components of the devices are made by plastic casting procedure. The metal frame is strapped to the body and supports wearer externally. Its several electronic motors act as artificial muscles to provide powered assistance to the wearer limbs. The first prototype of this orthosis assisted the subjects in order to stand up, walk, climb stairs, and perform a range of other leg movements [28].

3.7. Lower Extremity Exoskeleton (LEE). This project was undertaken by University of California and Berkeley Lower Extremity Exoskeleton.

3.8. Lowered Extremity Powered Exoskeleton (LEPE). This is one of the robotic systems implemented for gait rehabilitation by use of a treadmill training system. The system was developed using a series of Bowden cable driven of elastic actuators.

\section{Quality of the Research}

As there are not too many researches regarding evaluation of the performance of the subjects with SCI while walking and standing with external powered orthoses, the heterogeneity test cannot be used for most of them. Amongst various orthoses designed, the WBC orthosis was evaluated in two research studies. The heterogeneity of the results regarding this orthosis is very high. As in the first research, only one subject was selected compared with 5 subjects in the second research, the difference between the performance of the orthosis reported in these studies is related to the error which has occurred in the first research. The quality of this research studies is poor and is presented in Table 2 . 


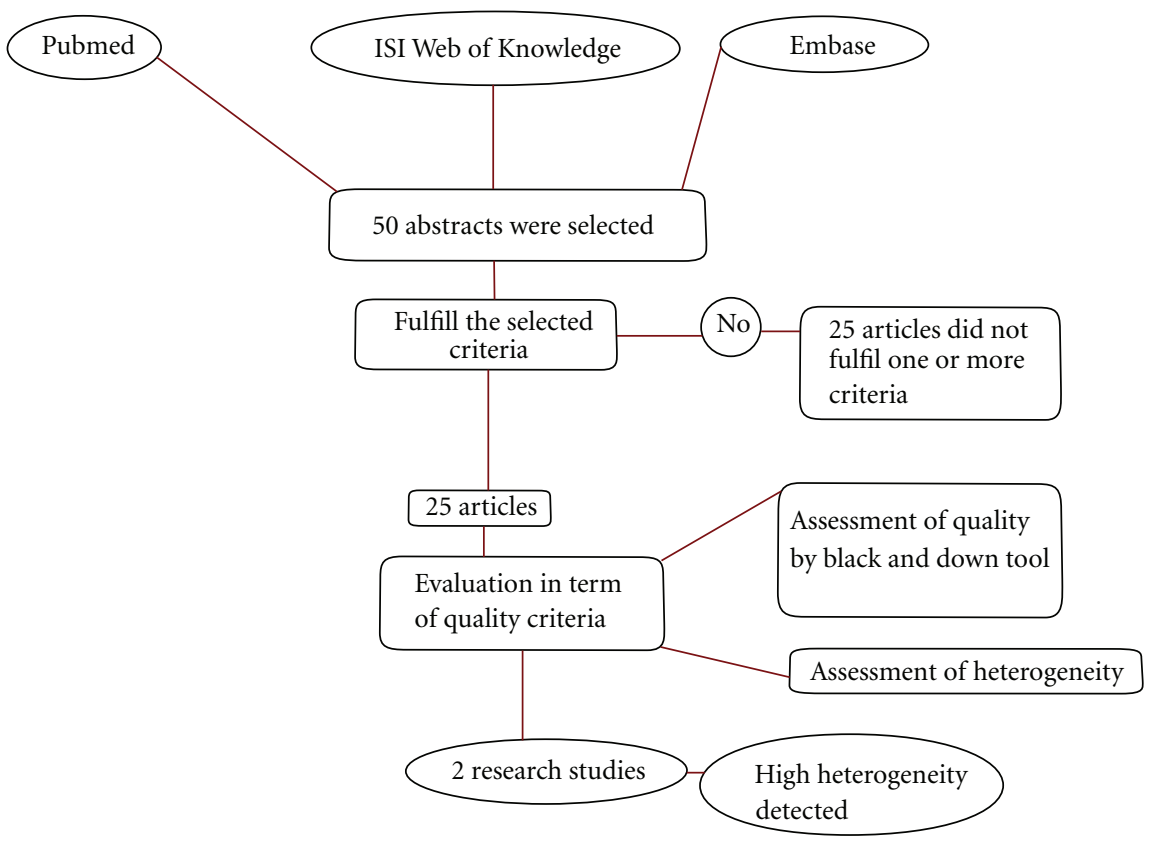

Figure 1: The stages which were selected in this research study.

TABLE 1: The results of quality assessment of methodology of various research studies (total number of studies was 25). PAGO: pneumatic active gait orthosis, PGO: powered gait orthosis, WBCO: weight bearing control orthosis, TDFO: two degree of freedom orthosis, DGO: driven gait orthosis, HAL: hybrid assistive limb and LEPE: lowered extremity powered exoskeleton.

\begin{tabular}{lcccc}
\hline Type of orthosis & Reporting (total score 10) & $\begin{array}{c}\text { External validity } \\
\text { (total score 3) }\end{array}$ & $\begin{array}{c}\text { Internal validity, bias } \\
\text { (total score 7) }\end{array}$ & $\begin{array}{c}\text { Internal validity, } \\
\text { confounding (total score 7) }\end{array}$ \\
\hline PAGO & 3 & 1 & 0 & 0 \\
PGO & 4 & 1 & 0 & 0 \\
WBCO & 7 & 3 & 3 & 3 \\
TDFO & 6 & 3 & 0 & 3 \\
DGO & 6 & 0 & 0 & 0 \\
HAL & 1 & 0 & 0 & 0 \\
Berkley orthosis & 1 & 0 & 0 & 0 \\
LEPE & 1 & 0 & 0 & 0 \\
\hline
\end{tabular}

TABLE 2: The energy consumption of the subjects while walking with WBC orthosis.

\begin{tabular}{|c|c|c|c|c|c|c|}
\hline Research & Number of subjects & Level of lesion & Energy consumption $(\mathrm{J} / \mathrm{kg} / \mathrm{s})$ & Energy cost $(\mathrm{J} / \mathrm{kg} / \mathrm{m})$ & PCI (beats/metre) & Speed $(\mathrm{m} / \mathrm{min})$ \\
\hline$[26]$ & 4 & T8-T12 & $5.41 \pm 0.65$ & $17.1 \pm 0.72$ & Not reported & $19 \pm 2.6$ \\
\hline$[25]$ & 1 & $\mathrm{~T} 12$ & Not reported & Not reported & 1.9 & 21.2 \\
\hline
\end{tabular}

The results of the research studies regarding the external powered orthoses are shown in Tables 2 and 3.

\section{Discussion}

Although it has been shown that various types of orthoses have been designed for paraplegic subjects to improve their performance, there is not too much research to evaluate their performance. Moreover, as can be seen from Table 1, the quality of the most research studies undertook on walking and standing of SCI individuals with external powered orthosis was not acceptable. Regarding the research done on the WBCO and TDFO, the aims and objective of the study were clearly defined. Moreover, the characteristics of the subjects include their age; level of injury was mentioned in detail. In these research studies, the main finding of the research entirely defined and appropriate statistical test was used to evaluate the difference between the results. But, in the other studies, most of the aforementioned procedures have not be done.

Unfortunately, the external validity of the most research done in this regard was not high as small number of subjects was selected. It was found that there was no attempt made to either blind the participants regarding the intervention 
TABLE 3: The gait performance of the subjects while walking with various orthoses.

\begin{tabular}{|c|c|c|c|c|c|c|c|c|}
\hline Research & $\begin{array}{l}\text { Number of } \\
\text { subjects }\end{array}$ & Level of lesion & Orthosis & $\begin{array}{l}\text { Speed } \\
(\mathrm{m} / \mathrm{min})\end{array}$ & $\begin{array}{l}\text { Stride length } \\
(\mathrm{cm})\end{array}$ & $\begin{array}{c}\text { Cadence } \\
\text { (stride/min) }\end{array}$ & $\begin{array}{l}\text { Lateral } \\
\text { amplitude } \\
(\mathrm{cm})\end{array}$ & $\begin{array}{l}\text { Vertical } \\
\text { amplitude } \\
(\mathrm{cm})\end{array}$ \\
\hline [25] & 1 & $\mathrm{~T} 12$ & WBCO & 21.2 & 55.2 & 38.4 & Not reported & Not reported \\
\hline$[27]$ & 5 & T5-T12 & $\begin{array}{c}\text { TDFO } \\
\text { without } \\
\text { actuator }\end{array}$ & $15-34$ & $80.9-122$ & Not reported & $4.5-42.7$ & $11.6-59$ \\
\hline$[27]$ & 5 & T5-T12 & $\begin{array}{c}\text { TDFO } \\
\text { with } \\
\text { actuator }\end{array}$ & $13.8-32.4$ & $78.7-119.4$ & Not reported & $3.7-57.6$ & $13.1-74$ \\
\hline
\end{tabular}

they received or to blind the researcher regarding the type of treatment used. Last but not least, most of the research did not have sufficient power to detect a clinically important effect as the number of participants was too limited.

5.1. DGO Orthosis. There are not too many researches done regarding the performance of this orthosis. Moreover, the quality of the available studies is low. The performance of the SCI subjects based on stability, gait parameters, and energy consumption has not been measured. However, the following parameters have been mentioned as the main advantages of this orthosis [19].

(1) The orthosis is adjustable in size, so different patients can use it.

(2) Several patients can be trained for more than half an hour, and a higher speed than a manually assisted walking can be selected.

(3) The gait pattern can be better adapted to the individual need.

(4) The automated training being more comfortable than the manually assisted one.

(5) Training sessions can be prolonged, and walking speed can be increased.

To authors' knowledge there is no research to support the above-mentioned advantages. It is recommended that the DGO orthosis cannot replace the therapist as this training can only be performed without the supervision of a qualified person. In only one research study was undertook in this field, the EMG activity of the leg muscles was compared for two training methods. It was found that there is no significant difference between the two training methods according to the leg muscles EMG activities.

5.2. TDFO Orthosis. As can be seen from Table 2, the performance of subjects has not improved while walking with the new orthosis in contrast to the mechanical orthosis. The results of the only research done in this regard show that the patients with a higher lesion level have less excursion in both lateral and vertical directions as the subjects swing paralyzed leg by help of external source instead of trunk muscles [27].

The other parameters which are very important are ease of donning and doffing of the orthosis and also the cosmesis of the orthosis. It seems that the patients have more problems to don and doff this orthosis in contrast to available mechanical orthoses. Moreover, cosmesis of this orthosis is a big issue especially with the actuators [27].

5.3. WBC Orthosis. There are only two research studies regarding this orthosis; however, the results have a high variability. As the number of participants in the first research study was only one, compared to five in the second study, therefore the accuracy of the results of the second study seems to be more than that of the first one. Based on the results of the second study, the performance of the subjects while walking with the WBC orthosis is less than that of the other available mechanical orthoses [14, 26, 2934]. Therefore, using some sources of power in an orthosis does not have a significant influence on improving the SCI individual's performance. Moreover, the subjects have more problems in order to don and doff the orthosis.

5.4. Other Orthoses. To authors' knowledge, there is not any research regarding evaluation of the performance of other orthoses on SCI function. Most of the orthoses have been tested on normal subjects. Although, some devices such as the HLO, hybrid assistive limb, and other lower extremity exoskeleton have special components to increase the performance of the subjects, most of them have been used for military purposes. They have been designed to be used by army in order to allow them to carry injured solders and also to bring food and first aid supplier to the area where vehicles cannot enter. They may help the subjects to stand up, climb stairs, and perform a variety of other leg movements. However, they have some problems which include

(1) an adequate power supply,

(2) recharging batteries which require especial facilities,

(3) cost and size of the system.

\section{Conclusion}

Various types of external powered orthoses have been designed for paraplegic subjects; however, most of them have been used in military purpose. Unfortunately, there is no good research regarding the performance of the subject with external powered systems. The performance of the subjects can be evaluated by standing stability, gait analysis, and by measuring energy consumption. Moreover, the cosmesis of the orthosis and the willingness of the subjects to use 
the orthoses are the other important parameters which need to be considered.

Although it has been shown that using some kinds of external powered orthosis such as DGO improves the performance of the subjects, there is no research to support it. Therefore, it is required to evaluate the performance of this orthosis in a randomized clinical trial.

\section{References}

[1] C. T. Liverman, Spinal Cord Injury: Progress, Promise, and Priorities, National Academies, Washington, DC, USA; Oxford Publicity Partnership, Oxford, UK, 2005.

[2] V. Nixon, Spinal Cord Injury: A Guide to Functional Outcomes in Physical Therapy Management, Heinemann, London, UK, 1985.

[3] M. F. Somers, Spinal Cord Injury: Functional Rehabilitation, Appleton \& Lange, Norwalk, Conn, USA, 1992.

[4] H. Y. Chen, S. S. Chen, W. T. Chiu et al., "A nationwide epidemiological study of spinal cord injury in geriatric patients in Taiwan," Neuroepidemiology, vol. 16, no. 5, pp. 241-247, 1997.

[5] P. J. O'Connor, "Prevalence of spinal cord injury in Australia," Spinal Cord, vol. 43, no. 1, pp. 42-46, 2005.

[6] I. Karacan, H. Koyuncu, O. Pekel et al., "Traumatic spinal cord injuries in Turkey: a nation-wide epidemiological study," Spinal Cord, vol. 38, no. 11, pp. 697-701, 2000.

[7] NSCISC, "Spinal cord injury: facts and figures at a glance," The Journal of Spinal Cord Medicine, vol. 24, no. 3, pp. 212-213, 2001.

[8] R. Douglas, P. F. Larson, R. D'Ambrosia, and R. E. McCall, "The LSU reciprocation-gait orthosis," Orthopedics, vol. 6, no. 7, pp. 834-839, 1983.

[9] American Academy of Orthopaedic Surgeons, Atlas of Orthotics, Mosby, St. Louis, Mo, USA, 2nd edition, 1985.

[10] J. W. Middleton, W. Fisher, G. M. Davis, and R. M. Smith, "A medial linkage orthosis to assist ambulation after spinal cord injury," Prosthetics and Orthotics International, vol. 22, no. 3, pp. 258-264, 1998.

[11] L. Sykes, J. Edwards, E. S. Powell, and E. R. S. Ross, "The reciprocating gait orthosis: long-term usage patterns," Archives of Physical Medicine and Rehabilitation, vol. 76, no. 8, pp. 779783, 1995.

[12] L. Sykes, E. R. S. Ross, E. S. Powell, and J. Edwards, "Objective measurement of use of the reciprocating gait orthosis (RGO) and the electrically augmented RGO in adult patients with spinal cord lesions," Prosthetics and Orthotics International, vol. 20, no. 3, pp. 182-190, 1996.

[13] J. W. Middleton, J. D. Yeo, L. Blanch, V. Vare, K. Peterson, and K. Brigden, "Clinical evaluation of a new orthosis, the 'Walkabout', for restoration of functional standing and short distance mobility in spinal paralysed individuals," Spinal Cord, vol. 35, no. 9, pp. 574-579, 1997.

[14] R. E. Major, J. Stallard, and G. K. Rose, "The dynamics of walking using the hip guidance orthosis (hgo) with crutches," Prosthetics and Orthotics International, vol. 5, no. 1, pp. 19-22, 1981.

[15] T. Engen, "Lightweight modular orthosis," Prosthetics and Orthotics International, vol. 13, no. 3, pp. 125-129, 1989.

[16] H. Ozyalcin and E. Ozbasli, "Hydraulic reciprocation gait hip knee ankle foot orthosis," in Proceedings of the 7th World Congress of ISPO, Chicago, Ill, USA, 1992.

[17] E. Genda, K. Oota, Y. Suzuki, K. Koyama, and T. Kasahara, "A new walking orthosis for paraplegics: hip and ankle linkage system," Prosthetics and Orthotics International, vol. 28, no. 1, pp. 69-74, 2004.

[18] G. Belforte, L. Gastaldi, and M. Sorli, "Pneumatic active gait orthosis," Mechatronics, vol. 11, no. 3, pp. 301-323, 2001.

[19] G. Colombo, M. Wirz, and V. Dietz, "Driven gait orthosis for improvement of locomotor training in paraplegic patients," Spinal Cord, vol. 39, no. 5, pp. 252-255, 2001.

[20] P. J. Greene and M. H. Granat, "A knee and ankle flexing hybrid orthosis for paraplegic ambulation," Medical Engineering and Physics, vol. 25, no. 7, pp. 539-545, 2003.

[21] A. V. Nene and J. H. Patrick, "Energy cost of paraplegic locomotion using the ParaWalker-electrical stimulation "hybrid" orthosis," Archives of Physical Medicine and Rehabilitation, vol. 71, no. 2, pp. 116-120, 1990.

[22] M. Solomonow, R. Baratta, S. Hirokawa et al., "The RGO generation II: muscle stimulation powered orthosis as a practical walking system for thoracic paraplegics," Orthopedics, vol. 12, no. 10, pp. 1309-1315, 1989.

[23] R. W. Barnett, Paraplegic Standing and Reciprocal Gait Using a Floor Reaction Hybrid F.E.S Orthosis, University of Strathclyde, Glasgow, UK, 1990.

[24] J. C. Ryu, S. J. Kang, I. H. Moon, J. W. Ryu, K. H. Kim, and M. S. Mun, "Foot-pressure distribution during the gait of paraplegic using PGO," in Proceedings of the 2nd International Conference of Biomedical Engineering, pp. 23-26, Innsbruck, Austria, 2004.

[25] H. Yano, S. Kaneko, K. Nakazawa, S. I. Yamamoto, and A. Bettoh, "A new concept of dynamic orthosis for paraplegia: the weight bearing control (WBC) orthosis," Prosthetics and Orthotics International, vol. 21, no. 3, pp. 222-228, 1997.

[26] N. Kawashima, Y. Sone, K. Nakazawa, M. Akai, and H. Yano, "Energy expenditure during walking with weightbearing control (WBC) orthosis in thoracic level of paraplegic patients," Spinal Cord, vol. 41, no. 9, pp. 506-510, 2003.

[27] Y. Ohta, H. Yano, R. Suzuki, M. Yoshida, N. Kawashima, and K. Nakazawa, "A two-degree-of-freedom motor-powered gait orthosis for spinal cord injury patients," Proceedings of the Institution of Mechanical Engineers, Part H, vol. 221, no. 6, pp. 629-639, 2007.

[28] R. Kobetic, C. S. To, J. R. Schnellenberger et al., "Development of hybrid orthosis for standing, walking, and stair climbing after spinal cord injury," Journal of Rehabilitation Research and Development, vol. 46, no. 3, pp. 447-462, 2009.

[29] J. Stallard and R. E. Major, "Case for lateral stiffness in walking orthoses for paraplegic patients," Proceedings of the Institution of Mechanical Engineers, Part H, vol. 207, no. 1, pp. 1-6, 1993.

[30] J. Stallard and R. E. Major, "The influence of orthosis stiffness on paraplegic ambulation and its implications for functional electrical stimulation (FES) walking systems," Prosthetics and Orthotics International, vol. 19, no. 2, pp. 108-114, 1995.

[31] P. Moore and J. Stallard, "A clinical review of adult paraplegic patients with complete lesions using the ORLAU ParaWalker," Paraplegia, vol. 29, no. 3, pp. 191-196, 1991.

[32] P. Butler, M. Engelbrecht, and R. E. Major, "Physiological cost index of walking for normal children and its use as an indicator of physical handicap," Developmental Medicine and Child Neurology, vol. 26, no. 5, pp. 607-612, 1984.

[33] J. Stallard, R. E. Major, and P. B. Butler, "The orthotic ambulation performance of paraplegic myelomeningocele children using the ORLAU ParaWalker treatment system," Clinical Rehabilitation, vol. 5, pp. 111-114, 1991.

[34] J. Stallard, ORLAU, A Brief History- The First 25 Years 1975 to 2000, ORLAU, 2000. 


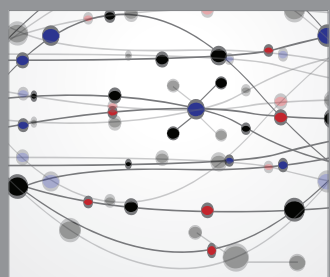

The Scientific World Journal
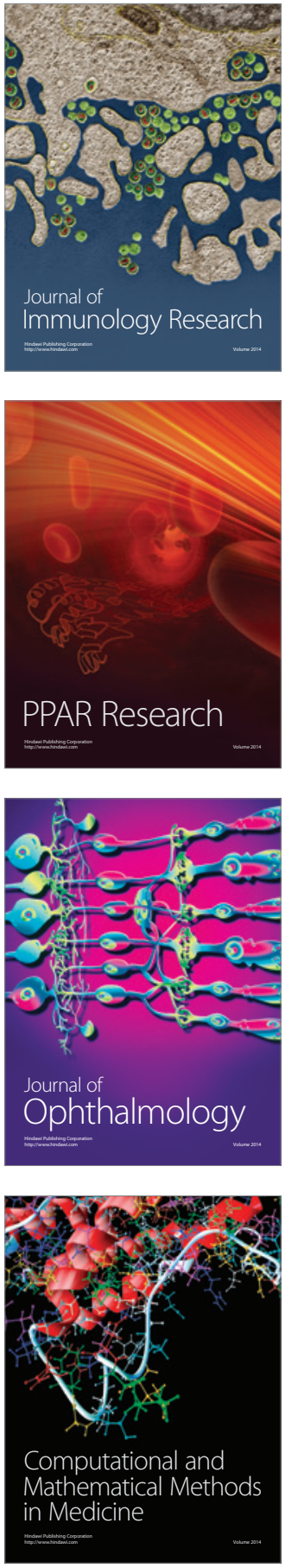

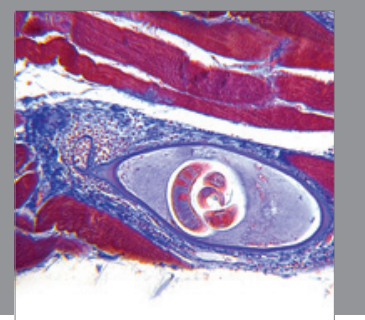

Gastroenterology

Research and Practice
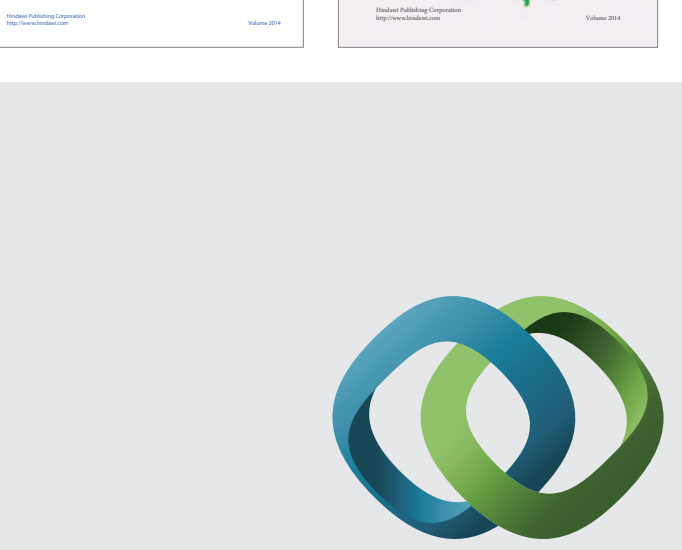

\section{Hindawi}

Submit your manuscripts at

http://www.hindawi.com
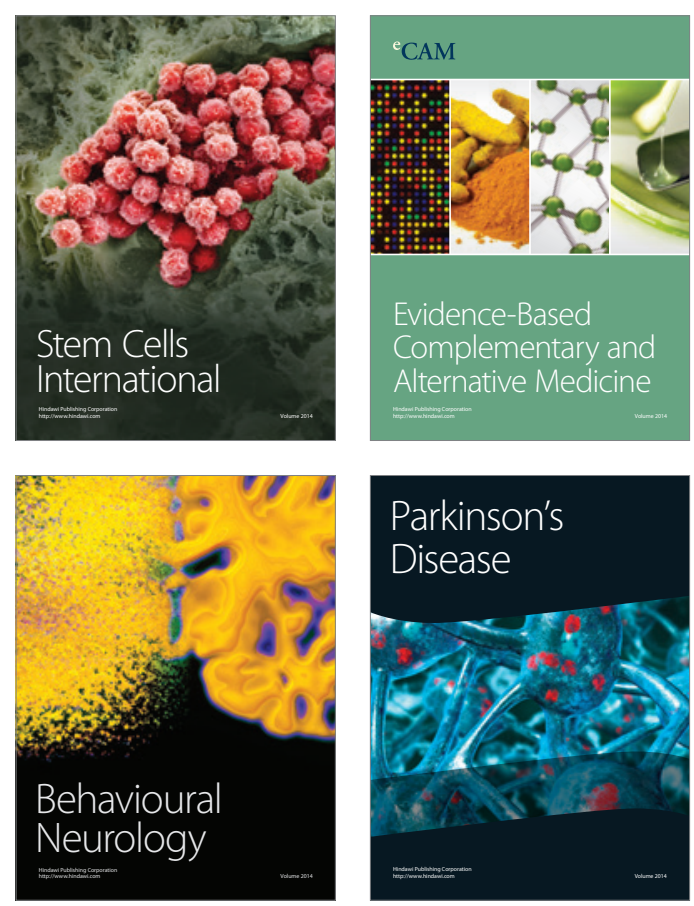

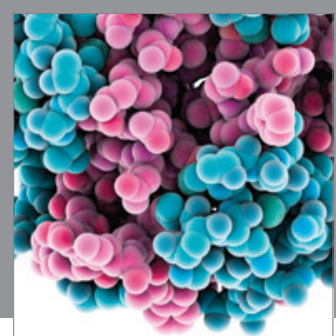

Journal of
Diabetes Research

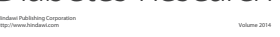

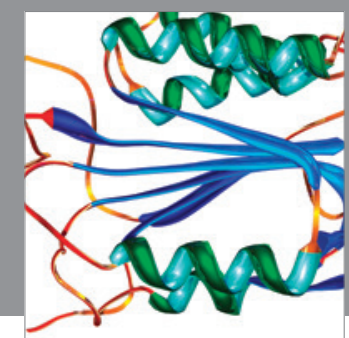

Disease Markers
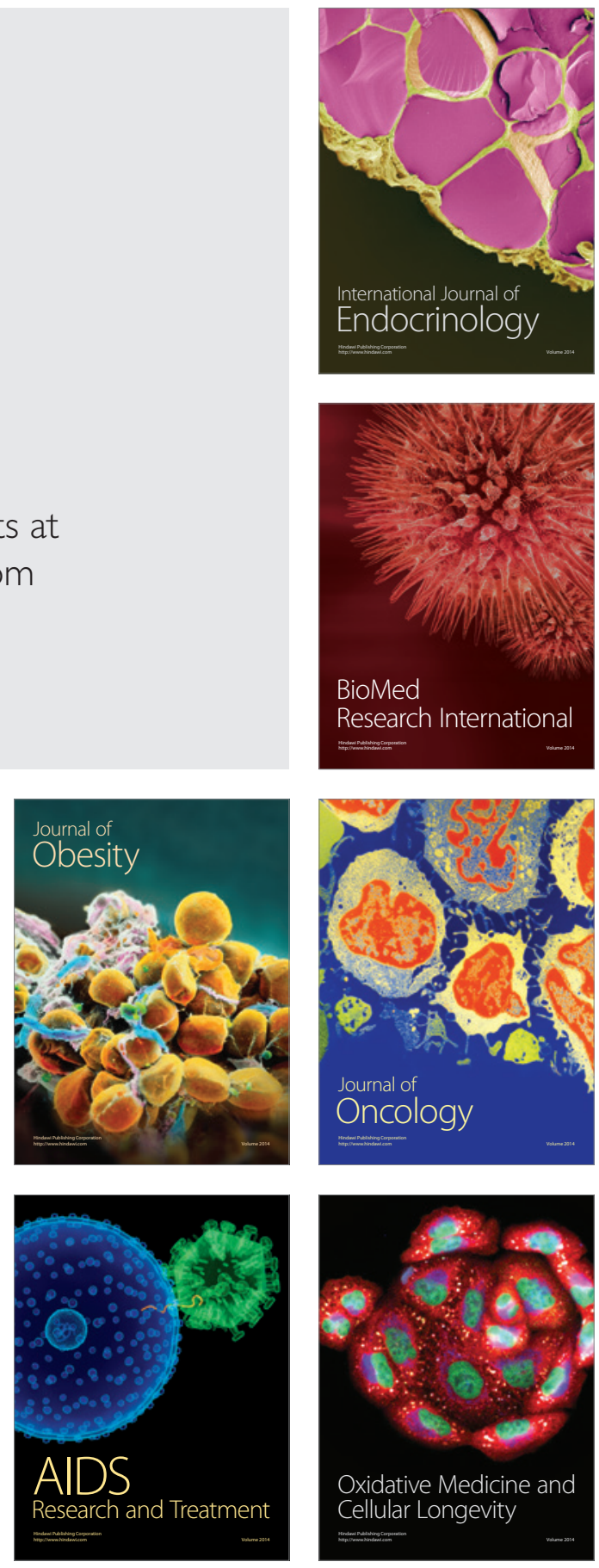